\title{
Ecologia do microfitoplâncton do estuário do rio Igarassu, PE, Brasil
}

\author{
Bruno Machado Leão ${ }^{1}$, José Zanon de Oliveira Passavante², \\ Maria da Glória Gonçalves da Silva-Cunha ${ }^{2,3}$ e Marilene Felipe Santiago ${ }^{2}$
}

Recebido em 5/12/2005. Aceito em 24/09/2007

\begin{abstract}
RESUMO - (Ecologia do microfitoplâncton do Estuário do Rio Igarassu, PE, Brasil). Foram realizadas coletas mensais de outubro/2002 a setembro/2003 em baixa-mar e preamar de um mesmo dia, para estudo da comunidade fitoplanctônica do estuário do rio Igarassu, relacionando-a aos parâmetros abióticos. Foram identificadas 210 espécies, distribuídas em cinco divisões. As Bacillariophyta tiveram maior representatividade, com 146 espécies, seguidas pelas Cyanophyta (26 espécies), Chlorophyta (15 espécies), Euglenophyta (12 espécies) e Dinophyta (11 espécies). As espécies dominantes foram Chaetoceros curvisetus Cleve (97,8\%, na preamar da estação 02, em abril/2003), Thalassionema nitzschioides Grunow (93,67\%, na estação 03, na baixa-mar, em agosto/2003), Microcystis aeruginosa Kützing (88,37\%, maio/2003, na baixa-mar da estação 02), Rhizosolenia hebetata (Bailey) Gran (87,52\%, na estação 03, na preamar de fevereiro/2003) e Thalassiosira rotula Meunier (84,18\% na estação 02, durante a preamar do mês de junho/2003). A densidade microfitoplanctônica esteve associada à pluviosidade, tendo ocorrido um florescimento expressivo no fim da período chuvoso e inicio do período de estiagem. A diversidade específica e equitabilidade estiveram diretamente relacionadas à baixa-mar e período de estiagem. A partir da observação dos parâmetros ambientais e da estrutura da comunidade fitoplanctônica verificou-se que existe uma forte influência da água do mar no estuário do rio Igarassu, evidenciada pela presença de espécies neríticas e oceânicas, enquanto que, na época de maior pluviosidade ocorreu à presença dominante da Cyanophyta dulcícola Microcystis aeruginosa Kützing.
\end{abstract}

Palavras-chave: microalgas, plâncton, diversidade, variação sazonal, estuário tropical

\begin{abstract}
Microphytoplankton Ecology of the Igarassu River Estuary, Pernambuco State, Brazil). Studies on the phytoplankton community and its relationship to abiotic parameters were carried out at the Igarassu River estuarine area. Plankton collections were made monthly from October/2002 to September/2003 during low and high tides on the same day. We identified 210 species, distributed in five divisions. Bacillariophyta was the most taxonomically diverse with 146 species, followed by Cyanophyta (26 species), Chlorophyta (15 species), Euglenophyta (12 species) and Dinophyta (11 species). The dominant species were Chaetoceros curvisetus Cleve (97.8\%, high tide, station 2, April/2003); Thalassionema nitzschioides Grunow (93.67\%, low tide, station 3, August/2003); Microcystis aeruginosa Kützing (88.37\%, low tide, station 2, May/2003); Rhizosolenia hebetata (Bailey) Gran (87.52\%, high tide, station 3, February/2003); and Thalassiosira rotula Meunier (84.18\% high tide, station 2, June/2003). Microphytoplankton density was related to rainfall, with a bloom at the end of the rainy season. Higher species diversity and evenness were related to low tide and dry season. The phytoplankton community was structured by the marine flux during the dry season in the Igarassu River estuary with the presence of neritic and oceanic species. In the rainy season the community was structured by the freshwater flux, with the dominance of the Cyanophyta Microcystis aeruginosa Kützing.
\end{abstract}

Key words: microalgae, plankton, diversity, seasonal variation, tropical estuary

\section{Introdução}

Os estuários são ambientes de alta produtividade, inseridos na porção costeira dos continentes, porém diferindo do ecossistema marinho costeiro por receber influência limnética e nerítica, possuindo tanto características de continuidade em variáveis ambientais, como a salinidade, e biológicas, como a estrutura das comunidades. Assim, os estuários poderiam ser considerados zonas de transição ou ecótonos entre os ecossistemas marinhos e limnéticos, não tendo, contudo, seus aspectos mais importantes do ponto de vista físico e/ou biológico, características transicionais, mas exclusivas (Odum 1988; Attrill \& Rundle 2002; Elliot \& McLusky 2002).

A alta produtividade destes ambientes ocorre em função dos nutrientes carreados pelo fluxo de água doce e da mistura vertical e turbulência ocorridas no encontro com a água marinha, que prende o material carreado na coluna d'água, de forma que os vegetais têm acesso a

\footnotetext{
1 Universidade Federal de Pernambuco, Programa de Pós Graduação em Biologia Vegetal

2 Universidade Federal de Pernambuco, Programa de Pós Graduação em Oceanografia, Departamento de Oceanografia, Av. Arquitetura s.n., Cidade Universitária, 50740-550 Recife, PE, Brasil

3 Autor para correspondência: gloria10@bol.com.br
} 
uma maior quantidade de fósforo e outros nutrientes. Dessa forma, os estuários funcionam, por suportarem uma elevada produção orgânica, como abrigo a várias espécies em todo o ciclo vital e formas juvenis de outras que passam apenas o início de suas vidas, além de organismos que migram para estes ambientes para reproduzir ou alimentarem-se, frente à maior proteção contra predadores e abundância de alimento. Neles são encontradas diversas espécies de peixes, moluscos, crustáceos, entre outros organismos, que dependem total ou parcialmente de seus recursos, sendo muitos de interesse econômico (Odum 1988).

Dentre os produtores primários do ecossistema estuarino, o fitoplâncton constitui uma das maiores fontes alimentícia aos herbívoros, transferindo energia sintetizada à teia trófica aquática. Esta dinâmica da comunidade fitoplanctônica é influenciada pela combinação dos fatores biológicos, climatológicos e hidrológicos dos estuários, sendo afetada pelas variações sazonais e diárias do ambiente, como pluviosidade, profundidade da zona eufótica, alterações do padrão de circulação da água e mudanças na sua composição química, sendo as alterações na composição do fitoplâncton refletidas em toda a biota estuarina (Brandini 1988; Boney 1989; Rezende \& Brandini 1997).

Da mesma forma, as interferências causadas pela ação humana promovem efeitos diversos na comunidade fitoplanctônica, através do lançamento de poluentes nas águas dos rios, entre outras formas de degradação, as quais promovem alteração na composição florística e na biomassa das microalgas.

Com isso, a determinação do comportamento e constituição do fitoplâncton é método eficaz para avaliação do ambiente, pela resposta dos organismos às mudanças físico-químicas da água, sendo as informações à respeito de sua variabilidade e abundância, bem como dos parâmetros abióticos do ecossistema, essenciais à definição de estudos e posteriores abordagens do local em questão (Round 1973; Cervetto et al. 2002).

O estuário do rio Igarassu integra parte do complexo estuarino do Canal de Santa Cruz, no Estado de Pernambuco, região de alta produtividade orgânica e intensa exploração pesqueira. Suas águas, além de utilizadas para essa atividade econômica, também funcionam como local de despejos urbanos e industriais, provocando graves desequilíbrios ao ecossistema (Macedo \& Costa 1990), além de provocar danos à saúde da comunidade ribeirinha.

Em face da importância sócio-econômica do rio Igarassu para a região e da má utilização de seus recursos, principalmente através do lançamento de poluentes em suas águas, foi realizado este estudo com o objetivo de registrar as mudanças na qualidade da água sob influencia das variações ambientais e seus reflexos na dinâmica do microfitoplâncton durante um período sazonal.

\section{Materiais e métodos}

$\mathrm{O}$ rio Igarassu nasce a sudoeste da cidade homônima, possui $10 \mathrm{~km}$ de extensão (CONDEPE 1982),

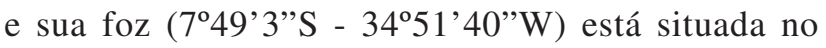
complexo estuarino do Canal de Santa Cruz, que separa a ilha de Itamaracá do continente. A ocupação de sua bacia dá-se por granjas e chácaras, silvicultura, policultura na porção superior, e cultivo de coco na porção central. No curso médio do rio Tabatinga existe o Refúgio Charles Darwin, área de conservação remanescente da Floresta Atlântica com 60 ha.

No trecho onde cruzam o perímetro urbano o rio Igarassu sofre degradação devido ao lançamento de resíduos de industrias do ramo têxtil, metalúrgica, alimentícia, química, sucro-alcooleira, de bebidas e de essências e de origem doméstica. Estes efluentes são responsáveis pelo comprometimento da qualidade da água, com níveis elevados de demanda bioquímica de oxigênio (D.B.O.) e reduzidos de oxigênio dissolvido no período de estiagem, além de altos teores de fósforo e níveis de coliformes fecais, em função do lançamento de esgotos domésticos, além de elevados valores de $\mathrm{pH}$ no período chuvoso (CPRH 2003; 2004). Neste ambiente foram selecionadas três pontos de coleta, nas porções superior, intermediária e inferior da área estuarina (Fig. 1).

Foram realizadas análises das variáveis abióticas do ecossistema estuarino do rio Igarassu e sua comparação e correlação com a composição taxonômica do microfitoplâncton, a partir de coletas mensais entre outubro/2002 e setembro/2003, nas preamares e baixamares do mesmo dia, em marés de sizigia. Os dados de pluviometria para a área de estudo foram obtidos na Estação Meteorológica do Curado, através do $3^{\circ}$ Distrito de Meteorologia (DISME), do Instituto Nacional de Meteorologia (INMET), correspondendo à precipitação mensal, de outubro/2002 a setembro/2003, e média histórica (período de 30 anos). A altura das marés foi obtida da Tábua das Marés para o ano de 2002 e 2003, da Diretoria de Hidrografia e Navegação (DHN) da Marinha do Brasil.

As amostras de água foram coletadas na superfície e no fundo com uma garrafa de Kitahara, de capacidade igual a $1 \mathrm{~L}$. A temperatura da água foi verificada por meio de termômetro digital, enquanto os dados de salinidade foram determinados através de refratômetro manual ATAGO. A profundidade local foi registrada através de um ecobatimetro, portátil Humminbird-Wide 100 a transparência da água foi registrada por meio de um disco de Secchi, e o coeficiente de extinção da luz, 


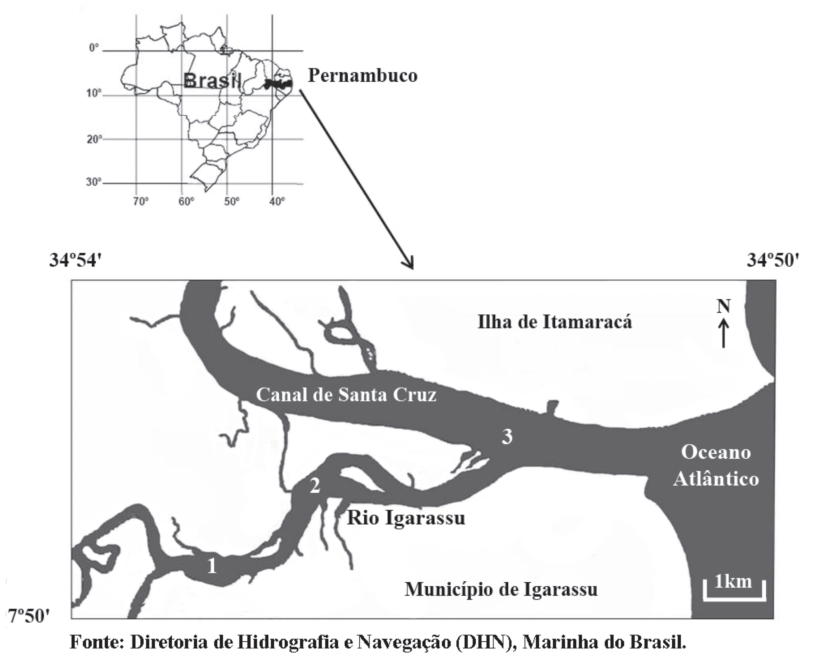

Figura 1. Localização dos pontos de coleta no estuário do rio Igarassu, PE, Brasil.

calculado a partir da profundidade do desaparecimento do disco de Secchi, utilizando-se a fórmula: $\mathrm{K}=1,7$ / D, onde $\mathrm{k}=$ coeficiente de extinção da luz; $\mathrm{D}=$ profundidade de desaparecimento do disco de Secchi; e 1,7 = constante. As analises de oxigênio dissolvido foram realizadas pelo método de Winkler, descrito por Strickland \& Parsons (1972), enquanto a taxa de saturação do oxigênio dissolvido foi determinada através das International Oceanographic Tables (UNESCO 1973).

As amostras de fitoplâncton foram coletadas em arrastos horizontais com duração de $3 \mathrm{~min}$, à velocidade de um nó $\left(1,852 \mathrm{~km} \mathrm{~h}^{-1}\right)$, com uma rede de plâncton de abertura de malha igual a $65 \mu \mathrm{m}$, sendo o material imediatamente fixado em formol neutro a $4 \%$. Foi realizada a análise quali-quantitativa das amostras, em câmara Sedgwich-Rafter, de $1 \mathrm{ml}$ de capacidade, com o auxílio do microscópio óptico com aumento final de 400x. A identificação taxonômica foi baseada em trabalhos especializados de Perágallo \& Perágallo (1897-1908), Prescott (1975), Sournia (1970), Sournia (1986). Para melhor identificação de algumas espécies de diatomáceas, utilizou-se o método proposto por Carr et al. (1986).

Foram calculadas a abundância relativa de acordo com Lobo \& Leighton (1986), a frequiência de ocorrência segundo Mateucci \& Colma (1982), a densidade celular (céls. $L^{-1}$ ), além da diversidade específica (Shannon 1948) e a equitabilidade (Pielou 1977).

A análise multivariada dos resultados foi realizada através da análise dos componentes principais, obtida do coeficiente de correlação momento-produto de Pearson, com a matriz inicial formada pela densidade celular das principais espécies do fitoplâncton $(\mathrm{F}>25 \%$ e/ou $\mathrm{A}>40 \%$ ) juntamente com os parâmetros ambientais, e do cálculo dos autovetores e autovalores da matriz de dispersão. Estas análises foram realizadas através do programa NTSYS (Numerical Taxonomy and Multivariate Analysis System), da Exeter Software, New York, EUA.

\section{Resultados}

A média pluviométrica mensal mostrou a ocorrência de um ciclo sazonal, caracterizado por um período chuvoso (março - agosto), e um período de estiagem (setembro - fevereiro), tendo valor máximo registrado em junho/2003 (474 mm) e o mínimo em dezembro/2002 (33,1 mm) (Fig. 2).

A altura das marés durante as baixa-mares foi variável de $0 \mathrm{~m}$ (maio/2003) a 0,6 m (dezembro/2002), e nas preamares de $1,9 \mathrm{~m}$ (dezembro/2002) a 2,4 m (março, abril e maio/2003). Quanto à profundidade local,foram registrados, na baixa-mar, valores de $0,7 \mathrm{~m}$ (outubro/2002) a $5 \mathrm{~m}$ (dezembro/2002); na preamar, estes valores foram de $2 \mathrm{~m}$ (novembro/2002 e janeiro/2003) a 6 m (junho/2003) (Fig. 3).

Foi observada uma variação sazonal da temperatura e salinidade (Fig. 4), sendo bem mais destacada apenas no segundo parâmetro. A temperatura da água variou de $23,6{ }^{\circ} \mathrm{C}$ (maio/2003) a $31,9^{\circ} \mathrm{C}$ (março/2003), enquanto a salinidade apresentou valores entre 2 (maio/2003) e 38( setembro/2003). Não sendo verificada significativa estratificação vertical destes componentes foi possível caracterizar o ambiente, de acordo com Pritchard (1955 apud Miranda et al. 2002), como estuário parcialmente misturado, sendo então considerados para efeito de estudo os dados da camada superficial. Observou-se, ainda, um gradiente de salinidade negativo em direção à montante, em proporção direta à altura das marés. A profundidade de desaparecimento do disco de Secchi, por sua vez, variou entre $0,15 \mathrm{~m}$ (maio/2003), na baixamar, e 2,76 m (janeiro/2003) na preamar, com respectivos

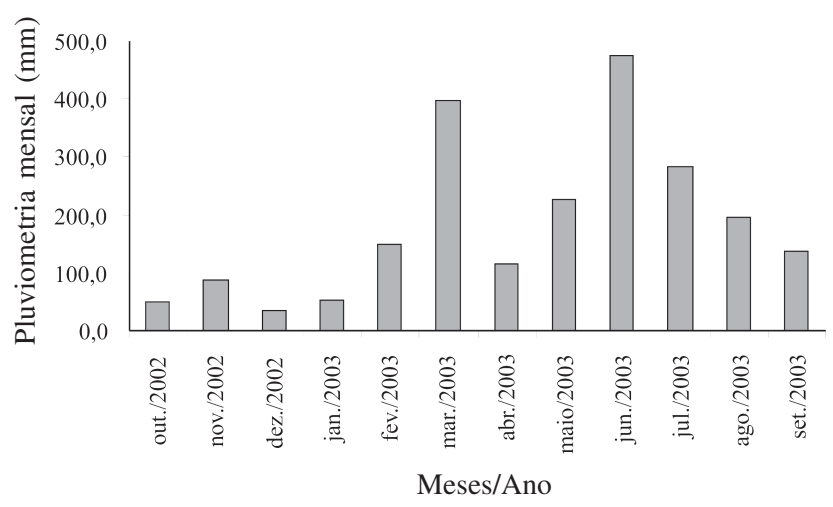

Figura 2. Variação da precipitação mensal (mm), registrada na Estação Meteorológica do Curado, Recife, PE, no período de outubro/2002 a setembro/2003. 
coeficientes de extinção da luz variando de 11,33 a 0,62 (Fig. 5).

Para o oxigênio dissolvido verificou-se teor mínimo de 1,54 mL.L ${ }^{-1}$ (janeiro/2003) e máximo de $6,55 \mathrm{~mL} . \mathrm{L}^{-1}$ (julho/2003). As concentrações deste elemento estiveram mais elevadas na preamar, na boca do estuário e no período estival. A taxa de saturação do oxigênio dissolvido apresentou também variação positiva rio abaixo, nos meses de menor pluviosidade e na preamar. $\mathrm{O}$ estuário apresentou-se, de acordo com Macedo \& Costa (1978), de semi-poluído, com menor taxa de $34,5 \%$ na estação 01, na baixa-mar (maio/2003) a saturado, na estação 03 em preamar (março/2003), com taxa de 154,6\% (Fig. $6)$.

No estuário do rio Igarassu foram identificadas 210 espécies fitoplanctônicas, distribuídas em cinco divisões. As Bacillariophyta tiveram maior representatividade, com 146 espécies, seguidas pelas Cyanophyta (26 espécies), Chlorophyta (15 espécies), Euglenophyta (12 espécies) e Dinophyta (11 espécies) (Tab. 1).

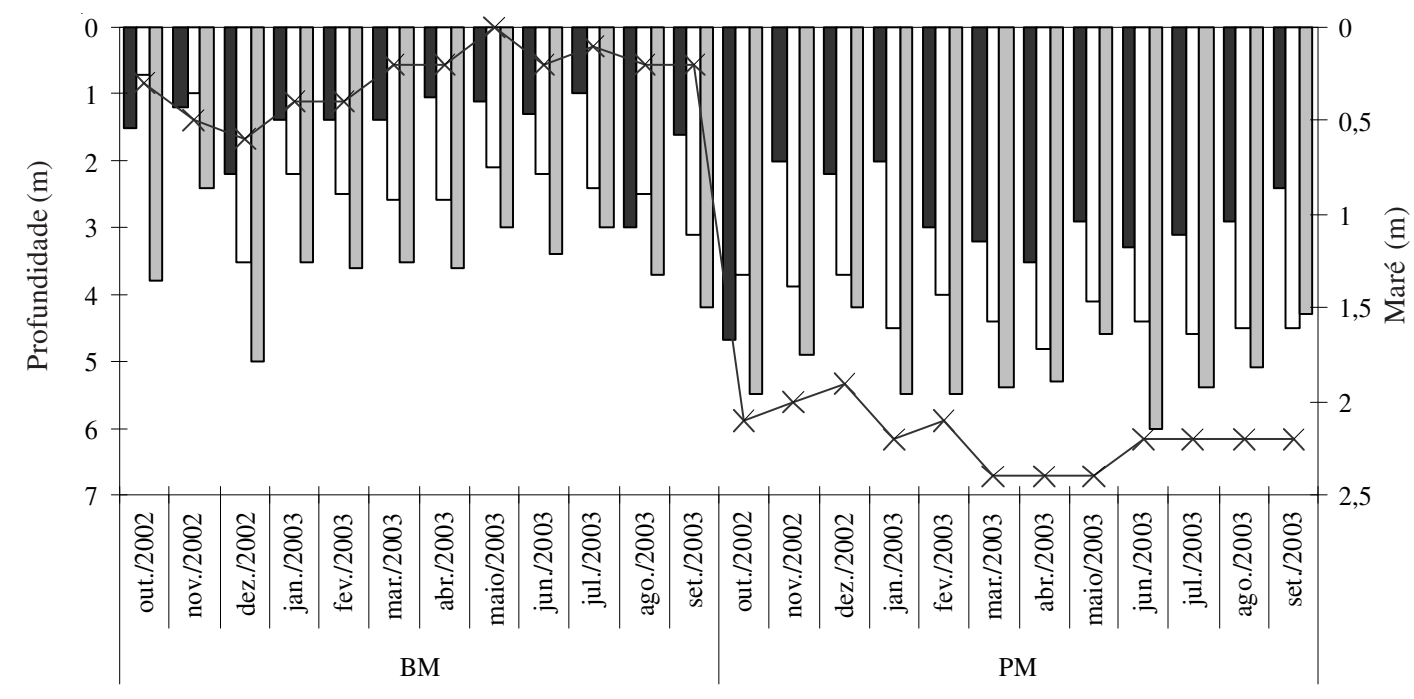

Figura 3. Variação da profundidade local (m) e maré no estuário do rio Igarassu, PE, Brasil, no período de outubro/2002 a setembro/2003. E1 - Estação 1; E2 - na Estação 2; E3 - Estação 3; BM - Baixa-mar; e PM - Preamar ( $\mathbf{\square}=\mathrm{E} 1 ; \square=\mathrm{E} 2$; $\square=\mathrm{E} 3$; * = Maré).

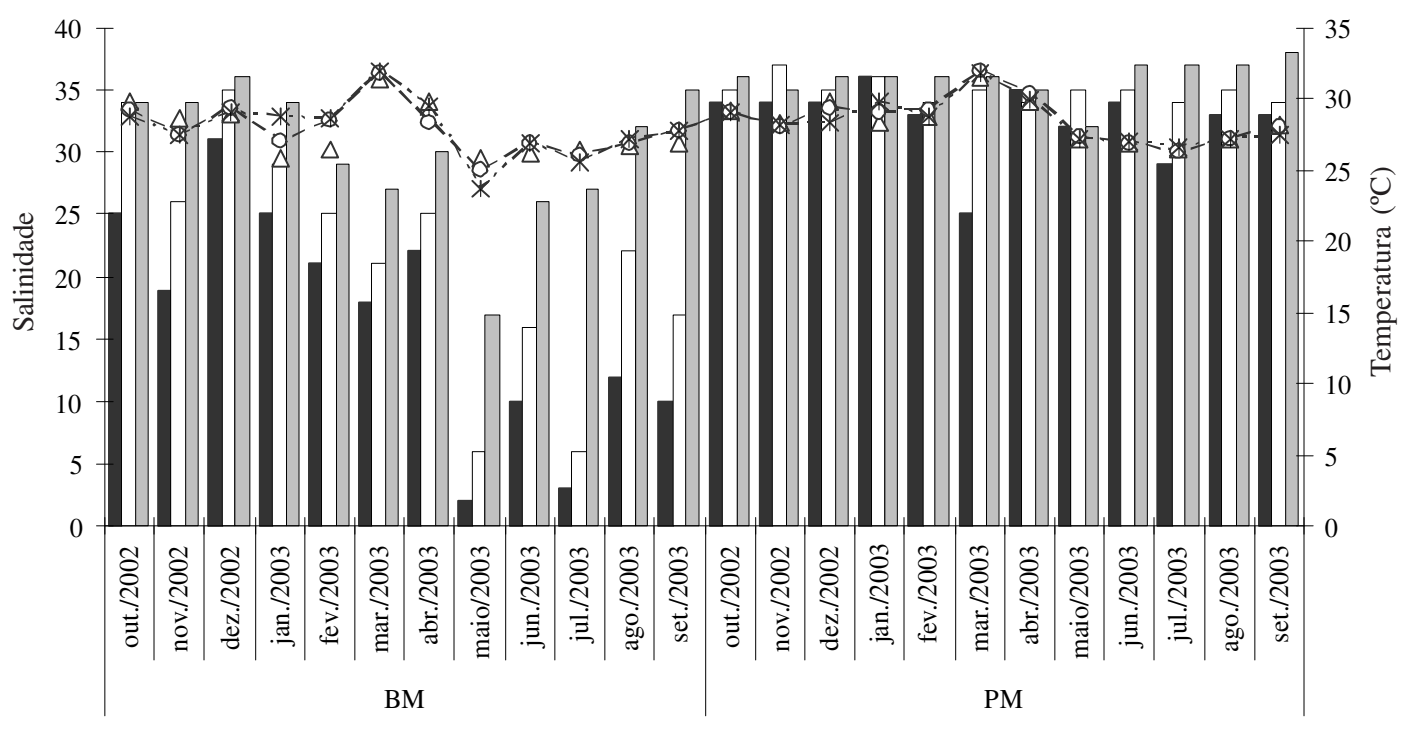

Figura 4. Variação da salinidade da água $(\mathrm{m})$ e temperatura da água $\left({ }^{\circ} \mathrm{C}\right)$ no estuário do rio Igarassu, PE, Brasil, no período de outubro/2002 a setembro/2003. E1 - Estação 1; E2 - na Estação 2; E3 - Estação 3; BM - Baixa-mar; e PM - Preamar $(\boldsymbol{\square}=\mathrm{E} 1 ; \square=\mathrm{E} 2 ; \mathbf{\square}=\mathrm{E} 3 ;-\triangle-=\mathrm{E} 1$; $-\mathrm{O}-\mathrm{E} 2$; - *- = E3). 
Cinco espécies apresentaram-se como dominantes no período de estudo, quatro abundantes, 17 pouco abundantes e 176 raras. As espécies dominantes foram Chaetoceros curvisetus, totalizando $97,8 \%$, na preamar da estação 02, em abril/2003; Thalassionema nitzschioides, 93,67\%, na estação 03, na baixa-mar, em agosto/2003; Microcystis aeruginosa, 88,37\%, com ocorrência da espécie unicamente em maio/2003, na baixa-mar da estação 02; Rhizosolenia hebetata, $87,52 \%$, na estação 03, na preamar de fevereiro/2003; e Thalassiosira rotula, com $84,18 \%$ dos organismos encontrados na estação 02 , durante a preamar do mês de junho/2003. Quanto à freqüência de ocorrência, três espécies foram muito freqüentes, 14 ocorreram como freqüentes, 49 pouco freqüentes e 136 foram registradas como raras (Fig. 7).

Com efeito, foram registrados valores de diversidade especifica com média na baixa-mar de 3,02 bits.cel $^{-1}$ na estação $01,2,75$ bits.cel $^{-1}$ na estação 02 e 2,68 bits.cel $^{-1}$ na estação 03. Na preamar, os registros médios foram de 2,40 bits.cel $^{-1}$, na estação $01,2,10$ bits.cel $^{-1}$ na estação 02, e 2,29 bits.cel $^{-1}$ na estação 03. Os valores mínimo e

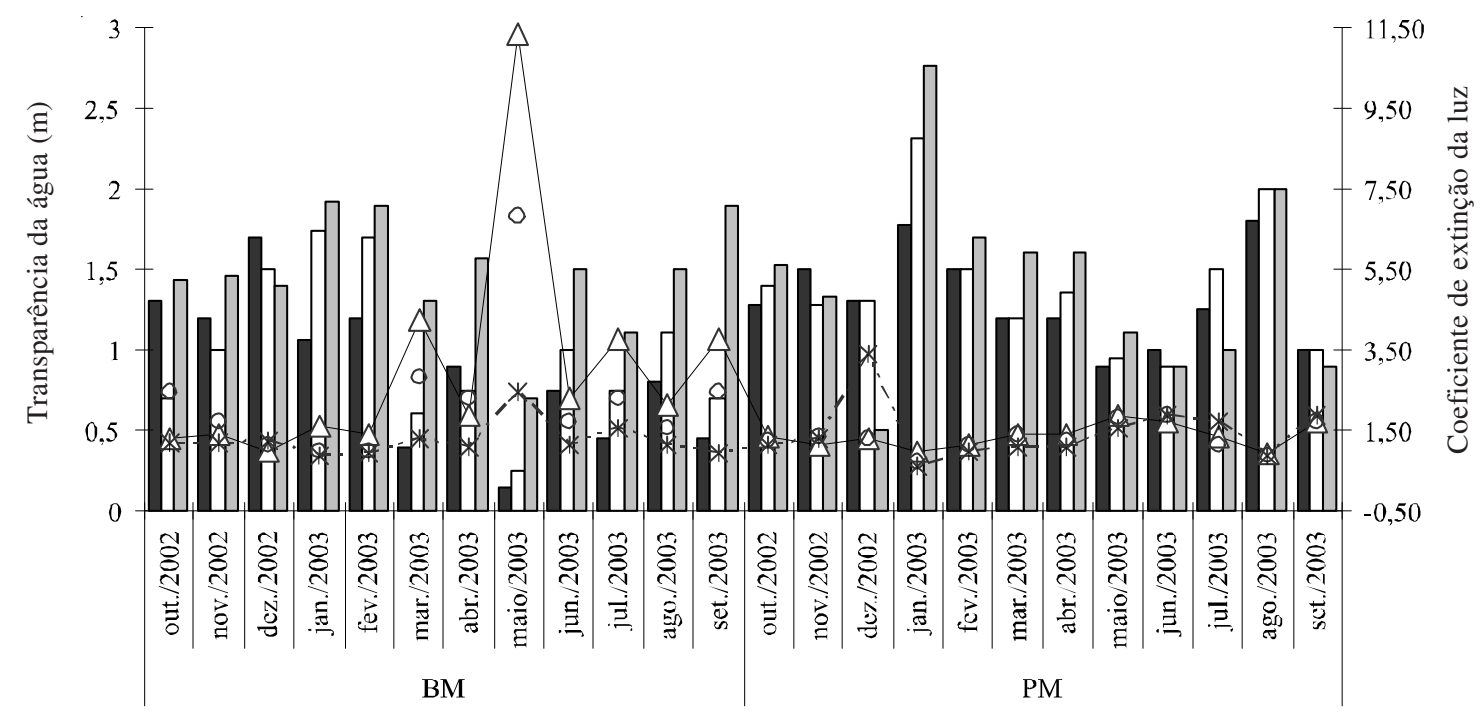

Figura 5. Variação da transparência da água (m) e coeficiente de extinção de luz no estuário do rio Igarassu, PE, Brasil, no período de outubro/2002 a setembro/2003. E1 - Estação 1; E2 - na Estação 2; E3 - Estação 3; BM - Baixa-mar; e PM - Preamar $(\square=$ E $1 ; \square=$ E2; - $\left.=\mathrm{E} 3 ;-\triangle-=\mathrm{E} 1 ;-\mathrm{O}_{-}=\mathrm{E} 2 ;-*_{-}=\mathrm{E} 3\right)$.

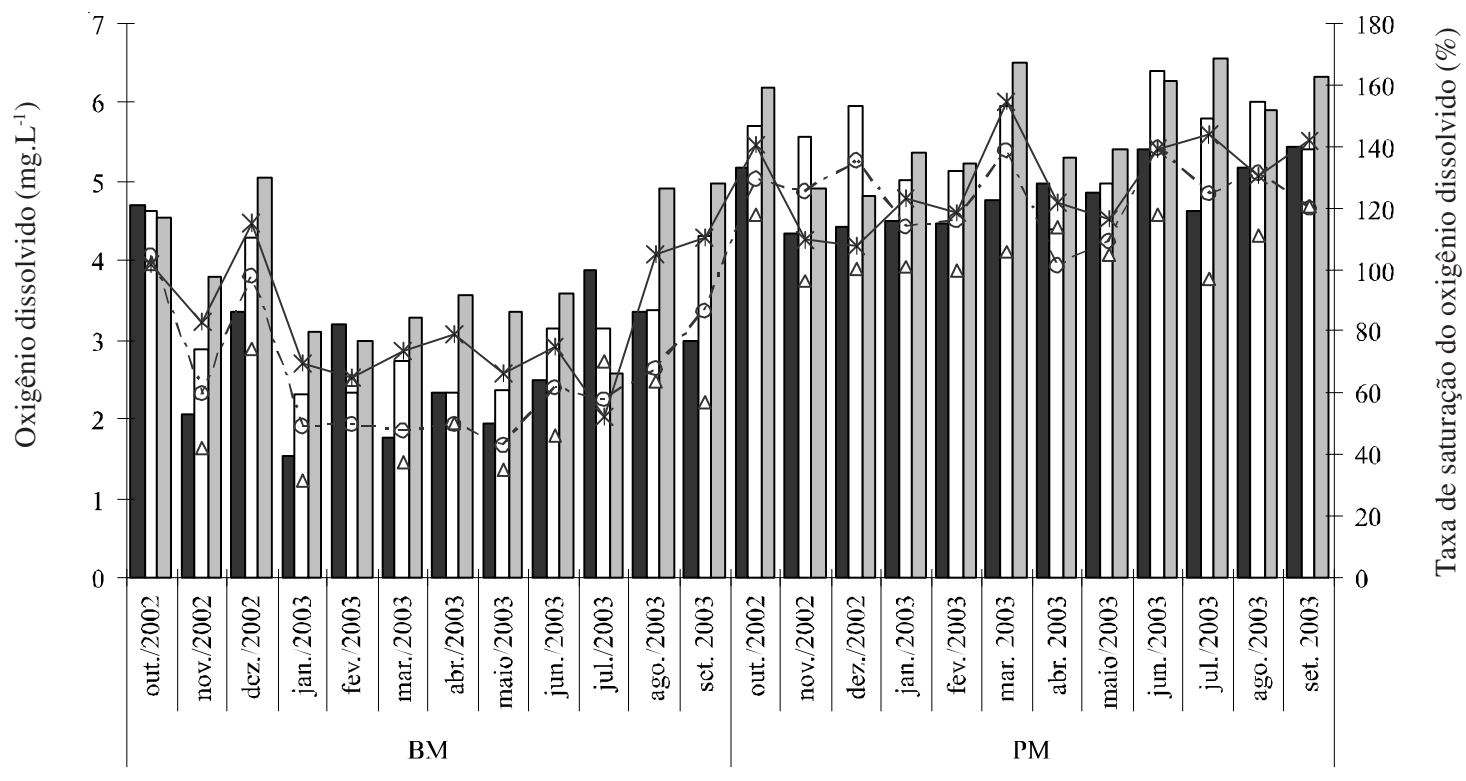

Figura 6. Variação do oxigênio dissolvido na água $\left(\mathrm{ml} . \mathrm{L}^{-1}\right)$ e taxa de saturação do oxigênio (\%) no estuário do rio Igarassu, PE, Brasil, no período de outubro/2002 a setembro/2003. E1 - Estação 1; E2 - na Estação 2; E3 - Estação 3; BM - Baixa-mar; e PM - Preamar ( $\mathbf{\square}=$ E 1; $\square=$ E2; $\left.\square=\mathrm{E} 3 ;-\triangle-=\mathrm{E} 1 ;-\mathrm{O}-=\mathrm{E} 2 ;-*_{-}=\mathrm{E} 3\right)$. 
Tabela 1. Táxons do microfitoplâncton encontrados no estuário do rio Igarassu, PE, Brasil, no período de outubro/2002 a setembro/2003.

\begin{tabular}{|c|c|}
\hline Táxons & Táxons \\
\hline CYANOPHYTA & A. fluminensis Grunow \\
\hline Anabaena constricta Szafer & A. hyalina Kützing \\
\hline Anabaena sp. & A. ostrearia Brébisson Kützing \\
\hline Aphanothece nidulans Richter & A. sulcata (Brébisson) Péragallo \\
\hline Aphanothece sp. & A. turgida Gregory \\
\hline Chroococcus pallidus Nägeli & A. veneta Kützing \\
\hline Chroococcus sp. & Amphora sp. \\
\hline Lyngbya sp. & Asterionellopsis glacialis (Castracane) Round \\
\hline Merismopedia convoluta Brébisson & Auliscus coelatus Bailey \\
\hline Microcystis aeruginosa Kützing & A. punctatus Bailey \\
\hline Microcystis sp. & A. sculptus (Smith) Ralfs \\
\hline Nostoc sp. & Bacillaria paxillifera (Müller) Hendey \\
\hline Oscillatoria amphibia Agardh & Bacteriastrum delicatulum Cleve \\
\hline O. curviceps Agardh & B. hyalinum Lauder \\
\hline O. ornata Kützing ex Gomont & Bellerochea malleus (Brightwell) Heurck \\
\hline O. perornata Skuja & Biddulphia laevis Ehrenberg \\
\hline O. princeps Vaucher & Caloneis westii (Smith) Hendey \\
\hline O. proteus Skuja & Campylodiscus clypeus Ehrenberg \\
\hline O. salina Biswas & C. fastuosus Ehrenberg \\
\hline O. sancta Kützing & Cerataulina pelagica (Cleve) Hendey \\
\hline O. subbrevis Schmidle & Cerataulus turgidus Ehrenberg \\
\hline Oscillatoria sp. & Chaetoceros affinis Lauder \\
\hline Spirulina gigantea Schmidle & C. atlanticus Cleve \\
\hline S. major Kützing Gomont & C. brevis Schütt \\
\hline S. subtilissima Kützing Gomont & C. compressus Lauder \\
\hline Spirulina sp. & C. constrictum Gran \\
\hline Stigonema sp. & C. costatus Pavillard \\
\hline EUGLENOPHYTA & C. curvisetus Cleve \\
\hline Euglena acus Ehrenberg & C. densus Cleve \\
\hline E. deses Ehrenberg & C. diversus CLeve \\
\hline E. oxyuris $\mathrm{Schmarda}$ & C. gracilis Schütt \\
\hline E. polymorpha Dangeard & C. lorenzianus Grunow \\
\hline Euglena sp. & C. mitra (Bayley) Cleve \\
\hline Phacus caudatus Huebner & C. pseudocurvisetus Mangin \\
\hline P. longicauda (Ehrenberg) Düjardin & C. socialis Lauder \\
\hline Phacus sp. & C. teres Cleve \\
\hline Trachelomonas abrupta Deflandre & C. wighami Brightwell \\
\hline T. armata Ehrenberg & Chaetoceros sp.1 \\
\hline T. volvocina Ehrenberg & Climacosphenia moniligera (Lyngbye) Kützing \\
\hline Trachelomonas sp. & Cocconeis scutellum Ehrenberg \\
\hline DINOPHYTA & Cocconeis sp. \\
\hline Glenodinium borgei (Lemmermann) Schiller & Coscinodiscus centralis Ehrenberg \\
\hline Goniodoma polyedricum (Pouchet) Jörgensen & C. granii Gough \\
\hline Gonyaulax poliedra Stein & C. oculusiridis Ehrenberg. \\
\hline Gonyaulax sp. & Coscinodiscus sp. \\
\hline Protoperidinium bispinum Schiller (Balech) & Cyclotella meneghiniana Kütz. \\
\hline P. grani Ostenfeld & Cylindrotheca closterium (Ehrenberg) Lew \\
\hline P. pentagonum Gran & Cymbella tumgida Brébisson \\
\hline Protoperidinium sp. & Cymbella sp. \\
\hline P. vulgare Balech & Diploneis bombus Ehrenberg \\
\hline Pyrocystis noctiluca Murray & Donkinia recta Grunow Heurck \\
\hline Pyrophacus horologium Stein & Entomoneis alata (Ehrenberg) Kützing \\
\hline BACILLARIOPHYTA & E. gigantea var. aequatorialis Cleve \\
\hline Actinoptychus senarius Ehrenberg & Entomoneis sulcata Meara \\
\hline A. splendens (Shadbolt) Ralfs & E. sulcata var. aequatorialis Cleve \\
\hline Actinoptychus sp. & Entomoneis sp. \\
\hline Amphora acuta Gregory & Fragilaria capucina Desmazieres \\
\hline Amphora arenaria Donkin & Grammatophora angulosa Ehrenberg \\
\hline A.coffeaformis (Agardh) Kützing & G. marina (Lyngbye) Kützing \\
\hline A. crassa Gregory & Guinardia striata (Stolterfoth) Hasle \\
\hline
\end{tabular}


Tabela 1 (continuação)

Táxons

Gyrosigma attenuatum (Kützing) Cleve

G. balticum (Ehrenberg) Cleve

G. fasciola var. sulcata (Grunow) Cleve

Hantzschia marina (Donkin) Grunow

Heliotheca thamensis Shrubsole (Ricard)

Licmophora abbreviata Agardh

L. communis Grunow

L. flabellata (Greville) Agardh

L. paradoxa Lyngbye (Agardh)

L. remulus Grunow

Licmophora sp.

Lithodesmium sp.

Lyrella lyra (Ehrenberg) Karayeva

Melchersiella hexagonalis Teixeira

Melosira nummuloides (Dillwyn) Agardh

Navicula lanceolata Kützing

N. meniscus Schumann

Navicula sp.

Nitzschia acuta Hantzchie

$N$. angularis Smith

N. apiculata (Gregory) Grunow

$N$. incurva Grunow

N. longissima (Brébisson) Grunow

$N$. lorenziana var. subtilis Grunow

$N$. pungens (Grunow ex Cleve) Hasle

$N$. sigma (Kützing) Smith

$N$. sigma var. intercedens Grunow

$N$. socialis Gregory

N. subtilis var. paleacea Grunow

$N$. tryblionella Hantzsch in Rabenhorst

$N$. vivax Smith

Nitzschia sp.

Odontella aurita (Lyngbye) Agardh

O. longicruris (Greville) Hoban

Paralia sulcata (Ehrenberg) Cleve

Pinnularia subtilis Gregory

Pinnularia sp.

Pleurosigma acuminatum Grunow

P. aestuarii (Brébisson) Smith

$P$. affine Grunow

$P$. angulatum Smith

P. angulatum var. strigosa (Smith)

$P$. delicatulum Smith

Pleurosigma diminutum Grunow

P. elongatum Smith

P. exsul Cleve

P. fasciola Smith
Táxons

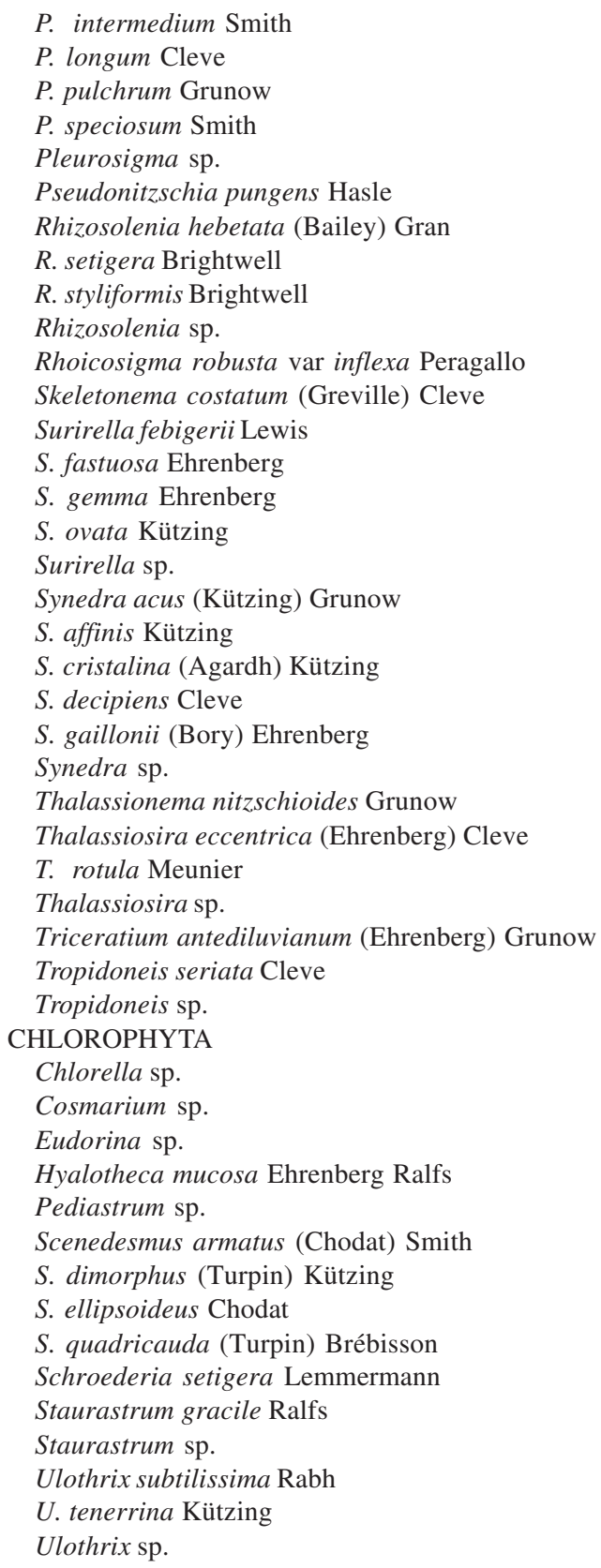

máximo foram de 0,25 bits.cel $^{-1}$ (abril/03), na preamar, e 4,07 bits.cel $^{-1}$ (março/03), na baixa-mar. Os valores de equitabilidade apresentaram médias de 0,61 na baixamar e 0,53 na preamar, com distribuição eqüitativa mais observada na baixa-mar. Em termos absolutos, foi observada variação de 0,07 (abril/2003) a 0,93 (março/2003), ambos na preamar (Tab. 2).

A flora planctônica esteve representada em sua maioria, por espécies ticoplanctônicas (ocasionais no plâncton), seguidas pelas dulcícolas, neríticas planctônicas, oceânicas planctônicas e estuarinas, sendo neríticas as espécies muito freqüentes, e as dominantes distribuídas entre neríticas, oceânicas, ticoplanctônicas e dulcícolas (Fig. 8). As maiores densidades celulares foram observadas nos meses de agosto e setembro/2003, onde foi registrada intensa precipitação pluviométrica no dia da coleta. Na baixa-mar a densidade variou de 25,97 cél. $L^{-1}$ na estação 03, em maio/2003 a 7996,33 cél. $L^{-1}$ na estação 03, em setembro/2003, enquanto na preamar a variação foi de 47,36 cél. $L^{-1}$ na 


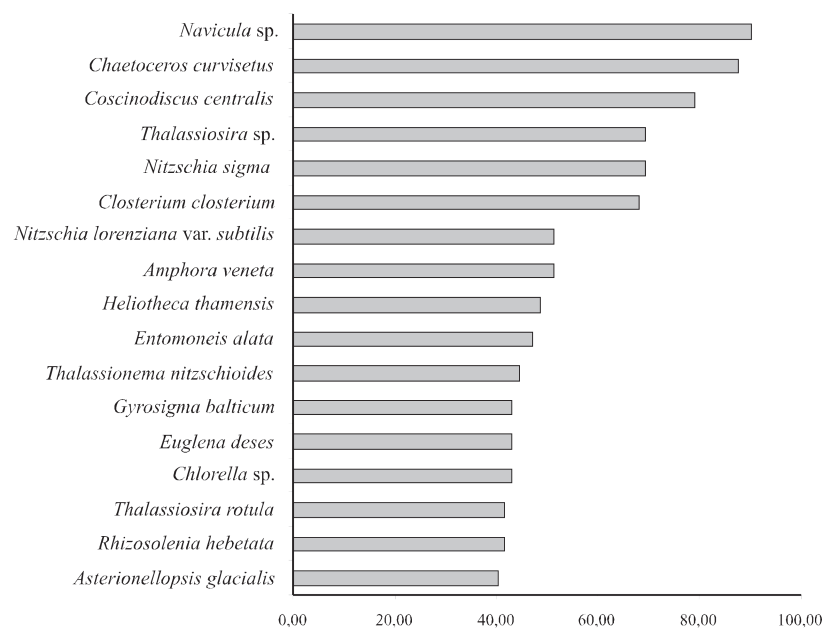

Figura 7. Freqüência de ocorrência das principais espécies do microfitoplâncton do estuário do rio Igarassu, PE, Brasil, no período de outubro/2002 a setembro/2003.

estação 02 , em novembro/2002, a 8586,05 cél.L $L^{-1}$ na estação 01 , no mês de setembro/2003, sendo observada uma variação sazonal deste parâmetro, principalmente em relação à preamar. Observa-se, então um florescimento expressivo no fim da estação chuvosa e inicio da estação de estiagem, e florescimentos secundários em outros meses, particularmente do período chuvoso, na estação 3, preamar (Tab. 2).

A análise dos componentes principais mostrou os três primeiros fatores explicando 51,45\% das variações registradas no estuário do rio Igarassu. Através do fator 1, que explicou $24,03 \%$ das variáveis, observou-se a correlação direta da diatomácea nerítica Coscinodiscus centralis com a dulcícola Nitzschia lorenziana var. subtilis e o coeficiente de extinção da luz, e inversa destes componentes à espécie nerítica Thalassionema nitzschioides e a oceânica Rhizosolenia hebetata, e os parâmetros altura da maré, profundidade, transparência da água, salinidade, concentração do oxigênio dissolvido e taxa de saturação do oxigênio. O fator 2 , responsável pela explicação de $17,35 \%$ das variações ocorridas, mostrou a correlação direta entre a espécie Navicula sp., a nerítica Chaetoceros curvisetus, a ticoplanctônica
Thalassiosira rotula, a estuarina Amphora veneta e a densidade celular, inversamente à diversidade específica e equitabilidade. Já o fator 3, que explicou 9,92\% das variações registradas, evidenciou a correlação direta entre as espécies ticoplanctônicas Cylindrotheca closterium e Nitzschia sigma, a espécie Thalassiosira sp e a temperatura da água, e inversa destes componentes com a cianofícea dulcícola Microcystis aeruginosa e a pluviosidade (Tab. 3).

\section{Discussão}

A conservação de ambientes estuarinos e a perpetuação do seu potencial econômico é alcançada através da abordagem dos principais problemas a eles relacionados, como também por meio do conhecimento das características comuns e únicas de cada estuário (Elliot \& McLusky 2002).

No estuário do rio Igarassu, tal como observado por Paranaguá et al. (1979) e Macêdo \& Costa (1990), a ação da maré promoveu a dinâmica dos parâmetros hidrológicos através do fluxo e refluxo marinho e a manutenção de sua composição biológica, verificados

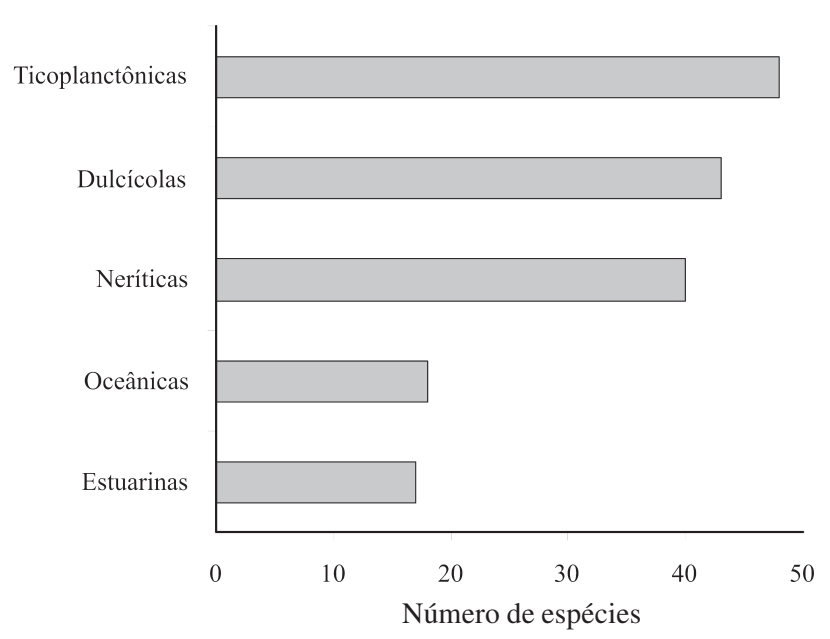

Figura 8. Distribuição ecológica das espécies do microfitoplâncton do estuário do rio Igarassu,PE, Brasil no período de outubro/2002 a setembro/2003. Os táxons em nível de gênero não foram considerados.

Tabela 2. Valore de densidade celular, diversidade especifica (bits.cel ${ }^{-1}$ ) e eqüitabilidade do microfitoplâncton do estuário do rio Igarassu, PE, Brasil, no período de outubro/2002 a setembro/2003. E1 - Estação 1; E2 - Estação 2; E3 - Estação 3.

\begin{tabular}{|c|c|c|c|c|c|c|c|c|c|c|}
\hline & \multicolumn{5}{|c|}{ Baixa-mar } & \multicolumn{5}{|c|}{ Preamar } \\
\hline & \multicolumn{3}{|c|}{ Valores médios } & \multirow{2}{*}{$\begin{array}{c}\text { Valor } \\
\text { mínimo }\end{array}$} & \multirow{2}{*}{$\begin{array}{c}\text { Valor } \\
\text { máximo }\end{array}$} & \multicolumn{3}{|c|}{ Valores médios } & \multirow{2}{*}{$\begin{array}{c}\text { Valor } \\
\text { mínimo }\end{array}$} & \multirow{2}{*}{$\begin{array}{l}\text { Valor } \\
\text { máximo }\end{array}$} \\
\hline & E1 & E2 & E3 & & & $\mathrm{E} 1$ & E2 & E3 & & \\
\hline Densidade celular $\left(\right.$ cel.L-1 $\left.{ }^{-1}\right)$ & 672,22 & 905,20 & 1352,46 & 25,97 & 7996,33 & 1857,26 & 1640,44 & 1085,22 & 47,36 & 8586,05 \\
\hline Diversidade Específica & 3,02 & 2,75 & 2,68 & 0,60 & 4,07 & 2,40 & 2,10 & 2,29 & 0,25 & 3,95 \\
\hline Eqüitabilidade & 0,65 & 0,60 & 0,58 & 0,32 & 0,89 & 0,53 & 0,51 & 0,55 & 0,07 & 0,95 \\
\hline
\end{tabular}


pela correlação direta de sua altura com a concentração de oxigênio dissolvido, salinidade e transparência da água, propiciando a introdução de espécies neríticas e oceânicas no ambiente, como Chaetoceros curvisetus e Rhizosolenia hebetata.

$\mathrm{O}$ ciclo de marés exerce, de fato, fundamental influência aos ambientes estuarinos, em função da renovação da água, de sua composição química e das comunidades biológicas, como a entrada de espécies eurialinas promovida pelo aumento da salinidade, promovendo ainda a diluição dos nutrientes e poluentes carreados pelo rio com conseqüente redução do nível de eutrofização nestes ambientes (Odebrecht 1988; Santos et al. 1997; Snow et al. 2000; Cerveto et al. 2002; Montes et al. 2002; Gameiro et al. 2004).

As variações no regime pluviométrico exerceram alterações na dinâmica do estuário, como a redução da transparência e da salinidade, devido ao aumento do fluxo limnético provocado durante os meses de maior pluviosidade, acarretando o aporte mais intenso dos rios, carreando maior teor de nutrientes e material em suspensão e promovendo assim, aumento do nível de mistura da água e incremento das condições eutróficas do ambiente. A correlação direta entre a pluviosidade e a espécie dulcícola Microcystis aeruginosa e inversa com as ticoplanctônicas Cylindrotheca closterium e Nitzschia sigma no estuário do rio Igarassu evidenciam a diminuição do nível de mistura e o aumento do caráter eutrófico do meio.

A salinidade atua de diferentes maneiras na ecologia dos estuários, constituindo o principal gradiente de distribuição da biota, regulando-a nos sentidos água doce-litoral e vice-versa, dependendo dos seres em questão, e tendo a intensidade do fluxo limnético como o segundo fator regulador (Attrill \& Rundle 2002).

Os valores de profundidade, salinidade e a transparência da água no estuário do rio Igarassu apresentaram-se semelhantes a outros ecossistemas da região de Pernambuco (Losada et al. 2000; Branco et al. 2002), estando correlacionadas diretamente à altura das marés e inversamente proporcionais à distância da jusante. Também foi observada a relação inversa da transparência em relação à período chuvoso, como conseqüência da lixiviação e carreamento de elementos do solo e do rio, bem como da ressuspensão do sedimento, alterando a profundidade da zona eufótica e, dessa forma, a composição da comunidade fitoplanctônica (Paranaguá et al. 1979; Macedo \&

Tabela 3. Contribuição dos táxons e parâmetros ambientais aos três primeiros componentes (fatores) principais no estuário do rio Igarassu, PE, Brasil.

\begin{tabular}{|c|c|c|c|}
\hline Parâmetros ambientais & $\begin{array}{l}\text { Fator } 1 \\
24,03 \%\end{array}$ & $\begin{array}{l}\text { Fator } 2 \\
17,35 \%\end{array}$ & $\begin{array}{l}\text { Fator } 3 \\
10,07 \%\end{array}$ \\
\hline Navicula sp. $^{1}$ & 0.0617 & $\underline{0.6970}$ & 0.5207 \\
\hline Chaetoceros curvisetus Cleve $^{1}$ & -0.1563 & $\underline{0.7790}$ & 0.2446 \\
\hline Cylindrotheca closterium Lewis ${ }^{1}$ & -0.0453 & $\overline{0.4639}$ & $\underline{0.4688}$ \\
\hline Thalassiosira sp. ${ }^{1}$ & -0.2951 & -0.1886 & $\overline{0.4658}$ \\
\hline Nitzschia sigma Smith $^{1}$ & 0.2524 & 0.0331 & $\underline{0.2965}$ \\
\hline Coscinodiscus centralis Ehrenberg ${ }^{1}$ & $\underline{0.3535}$ & -0.2009 & $\overline{0.0352}$ \\
\hline Thalassionema nitzschioides Grunow $^{1}$ & $\underline{-0.2311}$ & 0.1918 & -0.2078 \\
\hline Rhizosolenia hebetata Gran $^{1}$ & -0.2734 & -0.0298 & 0.0096 \\
\hline Thalassiosira rotula Meunier $^{1}$ & -0.3080 & $\underline{0.4585}$ & -0.4001 \\
\hline Amphora veneta Kützing $^{1}$ & 0.1259 & $\underline{0.7944}$ & 0.3475 \\
\hline Nitzschia lorenziana var. subtilis Grunow ${ }^{1}$ & $\underline{0.4783}$ & $\overline{0.3165}$ & 0.0519 \\
\hline Microcystis aeruginosa Kützing ${ }^{2}$ & $\overline{0.2346}$ & 0.1006 & $\underline{-0.4037}$ \\
\hline Densidade & -0.3408 & $\underline{0.8428}$ & $\overline{0.0791}$ \\
\hline Oxigênio dissolvido & $\underline{-0.9041}$ & 0.0082 & -0.1323 \\
\hline Taxa de saturação do oxigênio & $\overline{-0.9260}$ & -0.0456 & -0.0790 \\
\hline Temperatura da água & $\overline{-0.2697}$ & -0.2801 & $\underline{0.3752}$ \\
\hline Salinidade & -0.8552 & -0.2493 & 0.1865 \\
\hline Pluviosidade & $\overline{0.1501}$ & 0.0655 & $\underline{-0.4990}$ \\
\hline Transparência da água & -0.5797 & -0.2508 & 0.3675 \\
\hline Extinção da luz & $\underline{0.5904}$ & 0.2012 & -0.3913 \\
\hline Profundidade & $\underline{-0.8135}$ & -0.0928 & -0.1479 \\
\hline Altura da maré & -0.8199 & -0.1370 & -0.1705 \\
\hline Diversidade & 0.4128 & -0.6003 & 0.4100 \\
\hline Equitabilidade & 0.3626 & -0.6652 & 0.3295 \\
\hline
\end{tabular}

Os valores sublinhados correspondem aos componentes de cada fator. ${ }^{1}$ Bacillariophita; ${ }^{2}$ Cyanophyta. 
Costa 1990; Lacerda et al. 1998; Philips et al. 2002).

A temperatura da água, por sua vez, importante parâmetro na dinâmica das comunidades aquáticas em função da sucessão dos organismos (Boney 1989), apresentou discreta variação sazonal no ambiente estudado.

Além de influenciar, a concentração do oxigênio dissolvido, e sua taxa de saturação, é resultante da atividade fotossintética do fitoplâncton, das trocas entre as águas marinhas e fluviais, da transparência da água e salinidade. Outrossim, o elevado aporte de resíduos industriais e urbanos, associado à intensa atividade bacteriana e à diminuição da hidrodinâmica dos sistemas estuarinos atuam promovendo a depleção dos níveis de oxigênio na água (Santos et al. 1996; Campelo et al. 1999; Feitosa et al. 1999).

Tal como verificado por Macedo \& Costa (1990) e de acordo com a CPRH (2003), os poluentes lançados no rio Igarassu elevam os níveis de coliformes fecais e a demanda bioquímica de oxigênio, causando a diminuição do teor de oxigênio dissolvido, sendo este fator atenuado pela ação do fluxo de marés à jusante. Com isto, a classificação do estuário do rio igarassu, a partir da concentração do oxigênio dissolvido, foi variável de semi-poluído a saturado, em função da distância em relação à jusante e da altura das marés conforme a classificação adotada por Macedo \& Costa (1978).

A composição do fitoplâncton nos sistemas aquáticos fornece indícios do estado de conservação e eutrofização destes ambientes. Em meios livres da ação humana, o corpo d'água possui as características da vegetação, rochas e solo da região, enquanto em ambientes afetados pelo antropismo ocorre o enriquecimento dos cursos d'água pelo lançamento de fertilizantes, compostos de nitrogênio e fósforo, despejos domésticos não tratados e industriais, provocando eutrofização da água (Boney 1989). Dessa forma, a rápida entrada de nutrientes e minerais promovida pelas atividades humanas provoca alterações na estrutura das comunidades biológicas, observadas no plâncton através da substituição de espécies, aumento da biomassa e diminuição da diversidade específica (Persich et al. 1996).

A dominância das espécies neríticas e oceânicas no estuário do rio Igarassu esteve associada à influência das marés à jusante do rio, conforme a análise multivariada. De igual maneira, a pluviosidade permitiu, através da redução da salinidade, carreamento de material e ressuspensão do sedimento, a dominância de espécies dulcícolas e o transporte de espécies ticoplanctônicas para a coluna d'água.

A ocorrência e dominância das espécies marinhas Thalassionema nitzschioides, Thalassiosira rotula, Coscinodiscus centralis, Asterionellopsis glacialis e
Chaetoceros sp. foram associadas à influência marinha, fato também registrado em outros trabalhos como Eskinazi-Leça et al. (1980a), (1980b), Brandini (1988) e Orive et al. (1998), enquanto a cianofícea Microcystis aeruginosa e euglenofícea Euglena deses, foram relacionadas à baixa salinidade e elevadas concentrações de matéria orgânica, nitrogênio e fósforo (Brandini \& Thamm 1994; Mathiensen et al. 1999; Muyalert \& Raine 1999; Moncheva et al. 2001; Philips et al. 2002; Alves da Silva \& Hahn 2004). Dessa forma, e de acordo com os fatores citados, verificou-se que a dominância de espécies neríticas e oceânicas à jusante do estuário do rio Igarassu esteve possivelmente relacionada ao aumento dos aportes limnéticos durante o período chuvoso.

Em relação à diversidade específica, verifica-se ser este fator relacionado diretamente à complexidade do ecossistema, o qual aumenta em função da maturidade deste. Dessa forma, foi observado que graus intermediários da mistura da água permitem o máximo de diversidade específica, alcançado ao longo dos estágios da sucessão ecológica, com redução da dominância de umas poucas espécies precursoras e tendendo à igualdade quantitativa. O elevado grau de mistura da água, por outro lado, deve permitir a sobrevivência de uma ou poucas espécies resistentes a tais distúrbios até sua dominância, assim como ausência destes distúrbios a todos os organismos deve favorecer a competição, permitindo novamente a dominância de um ou poucos competidores (Margalef 1958 apud Valentin et al. 1991; Belgrano \& Brown 2002).

No rio Igarassu os períodos de baixa diversidade e equitabilidade estiveram associados à dominância das espécies neríticas e oceânicas, na estação mais à jusante e na preamar, enquanto a ocorrência de índices de baixa diversidade e equitabilidade se deu principalmente durante o período de estiagem e na baixa-mar, sendo resultado da ressuspensão do sedimento em pequenas profundidades, com conseqüente transporte de espécies ticoplanctônicas à coluna d'água, verificando-se o predomínio dessas espécies no ambiente. Essa contribuição dos organismos do fundo para a diversidade fitoplanctônica foi relatada por Facca et al. (2002), sendo neste último caso a ressuspensão do sedimento e espécies microfitobentônicas relacionadas a processos de dragagem realizados na Lagoa de Venice, Itália.

Feitosa et al. (1999), por sua vez, indicou semelhante ocorrência de baixos índices de diversidade específica no estuário do rio Goiana, resultante da dominância de espécies generalistas, sendo o referido ambiente impactado por resíduos de industrias sucroalcooleiras.

Em estuários onde a concentração de nutrientes é elevada, particularmente os degradados pelas atividades 
antrópicas, a luminosidade torna-se o fator limitante à produção fitoplanctônica, devido ao material em suspensão carreado pelo rio e trazido à coluna d'água pela hidrodinâmica (Cervetto et al. 2002; Lacerda et al. 1998; Schaub \& Gieskos 1991). Aliado a isso foi verificado a elevada ocorrência de espécies ticoplanctônicas tais como Nitzschia sigma e, particularmente, Cylindrotheca closterium, associada à ressuspensão do sedimento, à ocorrência de marés baixas e períodos de estiagem, responsáveis pela maior disponibilidade de luz à camada profunda, e ao lançamento de poluentes no corpo d'água (Nuccio et al. 2003; Gameiro et al. 2004; Su et al. 2004; Yap et al. 2004). A ocorrência elevada dessas espécies de acordo com estas características também foi verificada no ambiente deste presente trabalho.

A variação positiva da densidade celular do microfitoplâncton com a pluviometria e sua associação com a dominância de poucas espécies foi também observado por Brandini \& Thamm (1994) e Nuccio et al. (2003), que verificaram maior crescimento de determinadas espécies em condições apropriadas de luminosidade e de aportes limnéticos.

Através desses fatores e da associação das amostras pôde-se verificar a ocorrência no estuário do rio Igarassu de períodos de bom estado de conservação, nos quais ocorre o aumento da biodiversidade e a melhoria de suas condições hidrológicas, e períodos nos quais há a redução da qualidade do ambiente, a partir dos aportes continentais provocados pela elevação da pluviometria, com conseqüente depleção dos níveis de oxigênio dissolvido e taxa de saturação do oxigênio, e redução da diversidade específica do fitoplâncton.

Os resultados obtidos evidenciaram a existência de um gradiente de contaminação orgânica e eutrofização ao longo do estuário do rio Igarassu, entretanto verificou-se a importância da influência marinha para a manutenção do sistema, com a renovação da comunidade fitoplanctônica. Ainda, a eficiência do uso dessa comunidade na indicação de condições ambientais em cursos d'água foi comprovada, uma vez que houve concordância entre os resultado da análise multivariada utilizando dados de abundância de espécies e de variáveis ambientais.

\section{Agradecimentos}

À Coordenação de Aperfeiçoamento de Pessoal de Nível Superior (CAPES), pela concessão da bolsa de mestrado; ao Departamento de Oceanografia (UFPE), pela concessão do uso do Laboratório de Fitoplâncton; ao Prof. Dr. Éfrem Maranhão e Dra. Grácia Maranhão, por ter cedido a embarcação durante o período de coletas; ao técnico do laboratório do Departamento de Oceanografia Zinaldo Ferreira dos Santos, pelo apoio técnico.

\section{Referências bibliográficas}

Alves-da-Silva, S.M. \& Hahn, A.T. 2004. Study of Euglenophyta in the Jacuí Delta State Park, Rio Grande do Sul, Brasil.1. Euglena Ehr., Lepocinclis Perty. Acta Botanica Brasilica 18: 123-140.

Attrill, M.J. \& Rundle, S.D. 2002. Ecotone or ecocline: ecological boundaries in estuaries. Estuarine, Coastal and Shelf Science 55: 929-936.

Belgrano, A. \& Brown, J.H. 2002. Oceans under the macroscope. Nature 419: 128-129.

Boney, A. D. 1989. Phytoplankton. 2 ed. London, E. Arnold.

Branco, E.S.; Feitosa, F.A.N. \& Flores Montes, M.J. 2002. Variação sazonal e espacial da biomassa fitoplanctônica relacionada com parâmetros hidrológicos no estuário de Barra das Jangadas (Jaboatão dos Guararapes - Pernambuco - Brasil). Tropical Oceanography 30: 79-96.

Brandini, F.P. \& Thamm, C.A.C. 1994. Variações diárias e sazonais do fitoplâncton e parâmetros ambientais na baía de Paranaguá. Nerítica 8: 55-72.

Brandini, F.P. 1988. Composição e distribuição do fitoplâncton na região Sueste do Brasil e suas relações com as massas de água (Operação Sueste - julho/agosto 1982). Ciência e Cultura 4: 334-341.

Campelo, M.J.A.; Passavante, J.Z.A. \& Koening, M.L. 1999. Biomassa fitoplanctônica e parâmetros ambientais na praia de Carne de Vaca, Goiana, Pernambuco, Brasil. Trabalhos Oceanográficos 27: 27-41.

Carr, J.M.; Hergenrader, G.L. \& Troelstrup, N.H. 1986. A simple inexpensive method for cleaning diatoms. Transanctions of American Microsccopical Society 105: 152-157.

Cervetto, G; Mesones, C. \& Calliari, D. 2002. Phytoplankton biomass and its relationship to environmental variables in a disturbed coastal area of the Río de la Plata, Uruguay, before the new sewage collector system. Atlântica 24: 45-54.

CONDEPE (Companhia Pernambucana de Controle da Poluição Ambiental e de Administração dos Recursos Hídricos de Pernambuco). 1982. Estudo para controle ambiental nas áreas estuarinas de Pernambuco: Canal de Santa Cruz. Recife, CONDEPE.

CPRH (Companhia Pernambucana do Meio Ambiente). 2003. Relatório de monitoramento de bacias hidrográficas do Estado de Pernambuco - 2002. Recife, CONDEPE.

CPRH (Companhia Pernambucana do Meio Ambiente). 2004. Relatório de monitoramento de bacias hidrográficas do Estado de Pernambuco - 2003. Recife, CONDEPE.

Elliot, M. \& Mclusky, D.S. 2002. The need definitions in understanding estuaries. Estuarine, Coastal and Shelf Science 55: 815-827.

Eskinazi-Leça, E.; Passavante, J.Z.O. \& Barros-França, L.M. 1980a. Composição do microfitoplâncton do estuário do rio Igarassu (Pernambuco). Boletim do Instituto Oceanográfico 29: 163-167.

Eskinazi-Leça, E.; Macêdo, S.J. \& Passavante, J.Z.O. 1980b. Estudo ecológico da região de Itamaracá (Pernambuco-Brasil). V Composição e distribuição do microfitoplâncton do canal de Santa Cruz. Trabalhos Oceanográficos 15: 185-262.

Facca, C.; Sfriso, A. \& Socal, G. 2002. Changes in abundance and composition of phytoplankton and microphytobenthos due to increased sediment fluxes in the Venice Lagoon, Italy. Estuarine, Coastal and Shelf Science 54: 773-792.

Feitosa, F.A.N.; Silva-Cunha, M.G.G.; Passavante, J.Z.O.; NeumannLeitão, S. \& Lins, I.C. 1999. Estrutura do microfitoplâncton no sistema estuarino do rio Goiana, Pernambuco, Brasil. Trabalhos Oceanográficos 27: 15-25. 
Gameiro, C.; Cartaxana, P.; Cabritas, M.T. \& Brotas, V. 2004. Variability in chlorophyll composition in an estuarine system. Hydrobiologia 525: 113-124.

Lacerda, S.R.; Eskinazi-Leça, E. \& Koening, M.L. 1998. Composição e variação da flora das diatomáceas no estuário do rio Paripe (Itamaracá-Pernambuco-Brasil). Trabalhos Oceanográficos 26: $19-30$.

Lobo, E. \& Leighton, G. 1986. Estruturas comunitarias de las fitocenosis planctonicas de los sistemas de desembocaduras de rios y esteros de la zona central de Chile. Revista Biologia Marina 22: 1-29.

Losada, A.P.M.; Feitosa, F.A.N. \& Lins, I.C. 2000. Variação sazonal e espacial da biomassa fitoplanctônica nos estuários dos rios Ilhetas e Mamucaba (Tamandaré-PE) relacionada com parâmetros hidrológicos. Tropical Oceanography 28: 117-138.

Macêdo, S.J. \& Costa, K.M.P. 1978. Estudos ecológicos da região de Itamaracá. Pernambuco - Brasil. Condições Hidrológicas do Estuário do Rio Botafogo. Ciência e Cultura 30: 346- 368.

Macedo, S.J. \& Costa, K.M.P. 1990. Condições hidrológicas do estuário do rio Igaraçu - Itamaracá - Pernambuco. Trabalhos Oceanográficos 21: 7-32.

Mateucci, S.D. \& Colma, A. 1982. La metodologia para el estudo de la vegetacion. Collection de Monografias Cientificas 22: 1-168.

Matthiensen, A.; Yunes, J.S. \& Codd, G.A. 1999. Ocorrência, distribuição e toxicidade de cianobactérias no estuário da Lagoa dos Patos, RS. Revista Brasileira de Biologia 59: 361-376.

Miranda, L.B.; Castro, B.M. \& Kjerfve, B. 2002. Princípios de oceanografia física de estuários. São Paulo, EDUSP.

Moncheva, S.; Gotsis-Skretas, O.; Pagou, K. \& Krastev, A. 2001. Phytoplankton blooms in Black Sea and Mediterranean coastal ecosystems subjected to anthropogenic eutrophication: similarities and differences. Estuarine, Coastal and Shelf Science 53: 281-295.

Montes, M.J.F.; Macêdo, S.J. \& Koening, M.L. 2002. N:Si:P atomic ratio in the Santa Cruz Channel, Itamaracá-PE (Northeast Brazil): a nyctemeral variation. Brazilian Archives of Biology and Technology 45: 115-124.

Muyalert, K. \& Raine, R. 1999. Import, mortality and accumulation of coastal phytoplankton in a partially mixed estuary (Kinsale harbour, Ireland). Hydrobiologia 412: 53-65.

Nuccio, C.; Melillo, C.; Massi, L. \& Innamorati, M. 2003. Phytoplankton abundance, community structure and diversity in the eutrophicated Orbetello lagoon (Tuscany) from 1995 to 2001. Oceanologica Acta 26: 15-25.

Odebrecht, C. 1988. Variações espaciais e sazonais do fitoplâncton, protozooplâncton e metazooplâncton na Lagoa da Conceição, ilha de Santa Catarina,Brasil. Atlântica 10: 20-40.

Odum, E.P. 1988. Ecologia. Rio de Janeiro, Guanabara.

Orive, E.; Iriarte, A.; Madriarga, I. \& Revilla, M. 1998. Phytoplankton blooms in the Urbaidai estuary during summer: physico-chemical conditions and taxa envolved. Oceanologica Acta 21: 293-305.

Paranaguá, M.N.; Nascimento, D.A. \& Macedo, S.J. 1979. Estudo ecológico da região de Itamaracá, Pernambuco, Brasil. II. Distribuição do zooplâncton no estuário do rio Igarassu. Trabalhos Oceanográficos 14: 65-92.
Persich, G.R.; Odebrecht, C.; Bergesch, M. \& Abreu, P.C. 1996. Eutrofização e fitoplâncton: comparação entre duas enseadas rasas no estuário da Lagoa dos Patos. Atlântica 18: 27-41.

Péragallo, H. \& Péragallo, M. 1897-1908. Diatomées marines de France et des districts maritimes voisins. Paris, M.J. Tempère.

Philips, E.J.; Badylak, S. \& Grosskopf, T. 2002. Factors affeting the abundance of phytoplankton in a restricted subtropical lagoon, the Indian River Lagoon, Florida,USA. Estuarine, Coastal and Shelf Science 55: 385-402.

Pielou, E.C. 1967. Mathematical Ecology. New York, Wiley.

Prescott, G.W. 1975. Algae of the western great lakes area. Duduque, Wm. C. Brown.

Rezende, K.R.V. \& Brandini, F.P. 1997. Variação do fitoplâncton na zona de arrebentação da praia de Pontal do Sul (Paranaguá Paraná). Nerítica 11: 49-62.

Round, F.E. 1973. Biologia das algas. 2 ed. Rio de janeiro, Guanabara Dois.

Santos, E.D.; Abreu, P.C.; Thompson, F.L.; Hickenbick, G.R.; Almeida, M.T.A. \& Baumgarten, M.G. 1997. Poluição orgânica e condições sanitárias das águas próximas à cidade do Rio Grande - RS, Brasil (verão de 1996). Atlântica 19: 5-18.

Schaub, B.E.M. \& Gieskos, W.W.C. 1991. Eutrophication of the North Sea: the relation between Rhine river discharge and chlorophyll-a concentrations in Dutch coastal waters. In: M. Elliott \& J. P. Ducrotoy (eds.). Estuaries and coasts spatial and temporal intercomparisons. Olsen \& Olsen, Fredensborg.

Shannon, C.E. 1948. A mathematical theory of communication. Bulletin of System Technology Journal 27: 379-423.

Snow, G.C.; Adams, J.B. \& Bate, G.C. 2000. Effect of river flow on estuarine microalgal biomass and distribution. Estuarine, Coastal and Shelf Science 51: 255-266.

Sournia, A. 1986. Atlas du phytoplancton marin: introduction, Cyanophycées, Dictyochophycées, Dinophycées et Raphidophycées. v.1. Paris, Centre National de la Recherche Scientifique.

Sournia, A. 1970. A checklist of planktonic diatoms and dinoflagellates from the Mozambique Cannel. Bulletin Marine Science 20: 678-696.

Strickland, J.D.H. \& Parsons, T.R. 1972. A practical handbook of seawater analysis. 2 ed. Bulletin Fisheries Research board of Canada 167: 1-211.

Su, H.M.; Lin, H.J. \& Hung, J.J. 2004. Effects of tidal flushing on phytoplankton in a eutrophic tropical lagoon in Taiwan. Estuarine, Coastal and Shelf Science 61: 739-750.

UNESCO. 1973. International Oceanographic Tables. v.2. Wormley.

Valentin, J.L.; Macedo-Saidah, F.E.; Tenenmaum, D.R. \& Silva, N.M.L. 1991. A diversidade específica para a análise das sucessões fitoplanctônicas. Aplicação ao ecossistema da ressurgência de Cabo Frio (RJ). Neritica 6: 7-26.

Yap, L.G.; Azanza, R.V. \& Talaue-McManus, L. 2004. The community composition and production of phytoplankton in fish pens of Cape Bolinao, Pangasinan: a field study. Marine Pollution Bulletin 49: 819-832. 